\title{
Endoscopic metal enteral stent placement for malignant afferent loop syndrome after pancreaticoduodenectomy
}

\author{
Jiaxin Huang ${ }^{1}$, Sijie $\mathrm{Hao}^{1}$, Feng Yang ${ }^{1}$, Yang $\mathrm{Di}^{1}$, Lie $\mathrm{Yao}^{1}$, Ji Li ${ }^{1}$, Yongjian Jiang ${ }^{1}$, Liang Zhong ${ }^{2}$, Deliang Fu ${ }^{1}$, Chen Jin ${ }^{1}$ \\ ${ }^{1}$ Department of Pancreatic Surgery, Huashan Hospital, Fudan University, Shanghai, China \\ ${ }^{2}$ Department of Gastroenterology, Huashan Hospital, Fudan University, Shanghai, China
}

Videosurgery Miniinv 2015; 10 (2): 257-265

DOI: $10.5114 /$ wiitm.2015.51867

\begin{abstract}
Introduction: Afferent loop syndrome (ALS) is a rare and dreaded complication after pancreaticoduodenectomy (PD). Malignant ALS after PD is usually difficult to manage due to patients' poor condition. Effective and safe therapeutic strategies for these patients are reported scarcely at present.

Aim: To analyze and evaluate the clinical characteristics and treatment of these patients.

Material and methods: We analyzed 3 patients with malignant ALS after PD. They were treated by endoscopic enteral metal stent placement in our hospital. Meanwhile we retrospectively reviewed 49 cases with ALS after PD through available English literature. All these patients' clinical features, laboratory study, treatment and outcome were evaluated.

Results: A total of 52 cases were analyzed in the study. The most common presenting symptoms of ALS after PD were jaundice (56.5\%), upper abdominal pain (45.7\%), fever (26.1\%), and vomiting (23.9\%). Sixty percent of ALS cases were caused by tumor recurrence. The mean time from prior surgery to diagnosis of ALS was 13.3 months. The rates of treatment with the endoscopic approach, percutaneous stenting or drainage, surgery, and the conservative method were $40.4 \%, 32.7 \%, 11.5 \%$, and 15.4\%, respectively. Endoscopic enteral metal stent placement proved more effective and less invasive in the treatment of malignant ALS after PD.

Conclusions: Cholangitis and cholangiectasis are the major manifestations of malignant ALS after PD. Invasive interventions are enjoying more and more acceptance for treatment. Endoscopic enteral metal stent placement appears to be a promising technique with effective palliation in these patients.
\end{abstract}

Key words: pancreaticoduodenectomy, endoscopic treatment, afferent loop syndrome, metal enteral stent.

\section{Introduction}

Afferent loop syndrome (ALS) is defined as chronic, mechanical obstruction of the afferent loop resulting in pancreatobiliary problems after subtotal gastrectomies, Billroth-II procedures, pancreaticoduodenectomy (PD), or other gastrojejunostomies [1, 2]. Aoki et al. [3] reported that of 1908 patients after distal gastrectomy with Roux-en-Y reconstruction, the incidence of ALS was $0.2 \%$, which was slightly lower than the incidence of ALS after Billroth II gastrectomy (0.3-1.0\%). The obstruction could occur at any site of the afferent loop and is caused by a variety of postoperative complications, such as recurrent tumor, adhesion, kinking, structuring, or radiation enteritis alone or combined.

Afferent loop syndrome is a possible complication after PD. It is rarely reported and appropriate therapeutic strategies for ALS are rarely analyzed. As we know, the anatomical structure of the gastrointesti-

\section{Address for correspondence}

Chen Jin MD, PhD, Department of Pancreatic Surgery, Huashan Hospital, Fudan University, 12 Central Urumqi Road, 200040 Shanghai,

China, phone: +8613601981174 , e-mail: galleyking7036@126.com 
nal tract is more complicated after PD; the resulting anatomic changes vary from case to case depending on the surgery performed and the surgeon's preferences. Afferent loop syndrome could happen after $\mathrm{PD}$ due to the reconstruction of the gastrointestinal tract. Traditionally, surgical procedures are considered to be the best way to resolve this condition. In view of the patient's poor medical condition and the rapid development of interventional therapy, further surgical bypass is rarely a prior option, and a less invasive nonsurgical procedure such as the endoscopic approach and percutaneous transhepatic route is clearly desirable [4].

\section{Aim}

In this study, we review 52 cases of ALS following PD and discuss its clinical presentation, diagnosis, laboratory study, etiology, treatment and outcome. We assess the possible therapeutic strategies for malignant ALS following PD.

\section{Material and methods}

We retrospectively reviewed the clinical data of 3 cases admitted to Huashan Hospital, Fudan University, Shanghai, China, during a 2-year period from October 2011 to October 2013. A review of all English-language publications describing ALS following PD was done by searching the PubMed database and Web of Science database using the following terms: afferent loop/limb syndrome/obstruction and pancreaticoduodenectomy/Whipple procedure. Cases of ALS after PD were eligible for our study. Including all cases reported in relevant references and 3 cases in our hospital, 52 patients with ALS following PD were analyzed in this study. Data regarding patients' demographics, presentation, laboratory study, etiology, treatment and morbidity and mortality following treatment were extracted. Patients' data are shown in Table I.

\section{Results}

\section{Case 1}

A 65-year-old man was admitted to our hospital because of having an episode of fever for 10 days; the highest temperature was $40^{\circ} \mathrm{C}$. He had undergone a PD 12 months earlier due to adenocarcinoma in the head of the pancreas. The operation progressed without any major complications. The reconstruction was accomplished by the sequential placement of pancreatic, biliary and gastric anastomosis into the same jejunum loop. The reconstruction of the digestive tract was a Child type. Histopathological examination proved an RO (negative microscopic margins) resection. The patient had regular gemcitabine-based adjuvant chemotherapy after surgery. His laboratory data at the second admission were as follows: white blood cell count, $22.44 \times 10^{9} /$; total bilirubin, $26.3 \mu \mathrm{mol} / \mathrm{l}$; alanine aminotransferase, $118 \mathrm{U} / \mathrm{l}$. The serum amylase was normal. The performed abdominal computed tomography (CT) scan showed dilation of the afferent loop (Photo $1 \mathrm{~A}$ ) and biliary trees, and additionally a low-density lesion around the stenosis of the afferent loop, suggesting malignant ALS. For confirmation of the diagnosis and further management, peroral endoscopic exploration was performed with a colonoscope. A malignant stricture in the distal portion of the afferent loop was seen under the colonoscope. A guidewire was inserted across the stricture and a catheter was then passed along the guidewire to the dilated loop. Contrast agent was injected continually while removing the catheter back, and a $3 \mathrm{~cm}$ stricture was observed by X-ray (Photo $1 \mathrm{C}$ ). An uncovered metal stent (intestinal stent, Micro-Tech Nanjing Co., Ltd.), $20 \mathrm{~mm}$ in diameter and $60 \mathrm{~mm}$ in length, was successfully inserted through the stricture of the small bowel. The upper abdominal CT after management revealed that dilation of the afferent loop was alleviated (Photo 1 B). Afterward, the patient recovered from abdominal distention, pain and fever. He was discharged on the $3^{\text {rd }}$ day after endoscopic intervention in good general condition and had normal laboratory results. The patient died of disease progression 3 months later without evidence of recurrent ALS.

\section{Case 2}

A 55-year-old man presented with high-grade fever $\left(40^{\circ} \mathrm{C}\right)$ and upper abdominal pain for a week before being admitted to our hospital. The symptoms and signs were not relieved after antibiotic therapy. Four months before, the patient had undergone standard PD with Child reconstruction due to adenocarcinoma in the head of the pancreas. Histopathological examination showed an R1 (positive microscopic margins) resection. Gemcitabine-based adjuvant chemotherapy was performed after surgery. Results of major laboratory tests revealed the following abnormalities: total bilirubin, $162.1 \mu \mathrm{mol} / \mathrm{l}$; alanine aminotransferase, $189 \mathrm{U} / \mathrm{l}$; and alkaline phospha- 
Table I. Patients' data from the literature review

\begin{tabular}{|c|c|c|c|c|c|}
\hline First author & Cases & Manifestation & $\begin{array}{l}\text { Interval } \\
\text { [months] }\end{array}$ & Cause of ALS & Management \\
\hline Matsumoto [21] & 1 & $\begin{array}{c}\text { Abdominal pain, fever, } \\
\text { vomiting }\end{array}$ & 6 & Recurrent cancer & Endoscopic plastic stent \\
\hline Hosokawa [4] & 1 & $\begin{array}{l}\text { Abdominal pain, fever, } \\
\text { jaundice }\end{array}$ & 7 & Recurrent cancer & $\begin{array}{c}\text { Percutaneous transhepatic } \\
\text { metal stent }\end{array}$ \\
\hline $\operatorname{Han}[20]$ & 6 & NS & Mean 22 & $\begin{array}{l}\text { Recurrent cancer (5) } \\
\text { Adhesion (1) }\end{array}$ & $\begin{array}{l}\text { Percutaneous transhepatic } \\
\quad \text { metal stent (5). } \\
\text { Endoscopic metal stent (1) }\end{array}$ \\
\hline Pannala [1] & 24 & $\begin{array}{l}\text { Abdominal pain (7), } \\
\text { vomiting (5), jaundice } \\
\text { (12) }\end{array}$ & Mean 14 & $\begin{array}{l}\text { Recurrent cancer (8). } \\
\text { Radiation enteropathy (9). } \\
\text { Angulated/fixed limb (4). } \\
\text { Idiopathic (3) }\end{array}$ & $\begin{array}{l}\text { Endoscopic treatment (15). } \\
\text { Conservative (4). } \\
\text { PTBD (4). Percutaneous tran- } \\
\text { shepatic metal stent (1) }\end{array}$ \\
\hline $\operatorname{Kim}[22]$ & 2 & $\begin{array}{l}\text { Abdominal pain (1), } \\
\text { fever (1), jaundice (2) }\end{array}$ & 24,6 & Recurrent cancer (2) & Endoscopic metal stent (2) \\
\hline Juan [6] & 6 & $\begin{array}{l}\text { Abdominal pain (4), } \\
\text { fever (1), vomiting (4), } \\
\text { jaundice (2) }\end{array}$ & $7.8 \pm 4.6$ & NS & $\begin{array}{c}\text { Surgery (2). } \\
\text { Conservative (3) }\end{array}$ \\
\hline Laasch [7] & 2 & Jaundice (2) & 6,12 & Recurrent cancer (2) & $\begin{array}{l}\text { Percutaneous transhepatic } \\
\text { metal stent (1). } \\
\text { Direct percutaneous stent (1) }\end{array}$ \\
\hline Spiliotis [23] & 1 & $\begin{array}{l}\text { Abdominal pain, fever, } \\
\text { jaundice }\end{array}$ & 10 & Adhesion & Surgery \\
\hline Aimoto [5] & 2 & $\begin{array}{l}\text { Abdominal pain (2), } \\
\text { fever (2), jaundice (1) }\end{array}$ & 12,12 & Recurrent cancer (2) & Surgery (2) \\
\hline Chevallier [24] & 1 & $\begin{array}{l}\text { Abdominal pain, fever, } \\
\text { vomiting, jaundice }\end{array}$ & 19 & Recurrent cancer & Surgery \\
\hline Johnsson [17] & 1 & Jaundice & 18 & Recurrent cancer & $\begin{array}{l}\text { Percutaneous transhepatic } \\
\text { metal stenting }\end{array}$ \\
\hline Burdick [16] & 1 & $\begin{array}{l}\text { Abdominal pain, fever, } \\
\text { vomiting, jaundice }\end{array}$ & 7 & NS & Endoscopic metal stent \\
\hline Moriura [12] & 1 & Jaundice & 12 & Recurrent cancer & $\begin{array}{c}\text { Percutaneous external } \\
\text { drainage }\end{array}$ \\
\hline
\end{tabular}

tase, $769 \mathrm{U} / \mathrm{l}$. An abdominal CT scan revealed a dilated fluid-filled loop located at the mid-abdomen. The configuration of the afferent loop was also found to be a "C" character and keyboard sign on CT scan (Photo 2 A). A retroperitoneal low-density lesion and abnormal signals around the celiac trunk suggested local recurrence of cancer. After the diagnosis of malignant ALS, we chose the management of endoscopic enteral stent placement. Obstruction was found in the afferent loop $20 \mathrm{~cm}$ distal to the gastrojejunal anastomosis under the endoscope. An uncovered metal stent (intestinal stent, Micro-Tech Nanjing Co., Ltd.) $20 \mathrm{~mm}$ in diameter and $80 \mathrm{~mm}$ in length was inserted through the stricture. After stent placement, the dilated afferent loop showed a reduction in size on the $\mathrm{CT}$ scan (Photo $2 \mathrm{~B}$ ). There were no intraoperative or postoperative complications. The patient made an uneventful recovery before discharge on the fourth day postoperatively. The patient died of widespread carcinomatosis 3 months later without recurrence of ALS.

\section{Case 3}

A 68-year-old man was admitted to our hospital with high-grade fever $\left(40^{\circ} \mathrm{C}\right)$ and right upper abdominal pain. Seventeen months before, the patient had undergone standard PD with Child reconstruction due to adenocarcinoma in the head of the pancreas. Gemcitabine-based adjuvant chemotherapy was performed after surgery. Results of liver function 

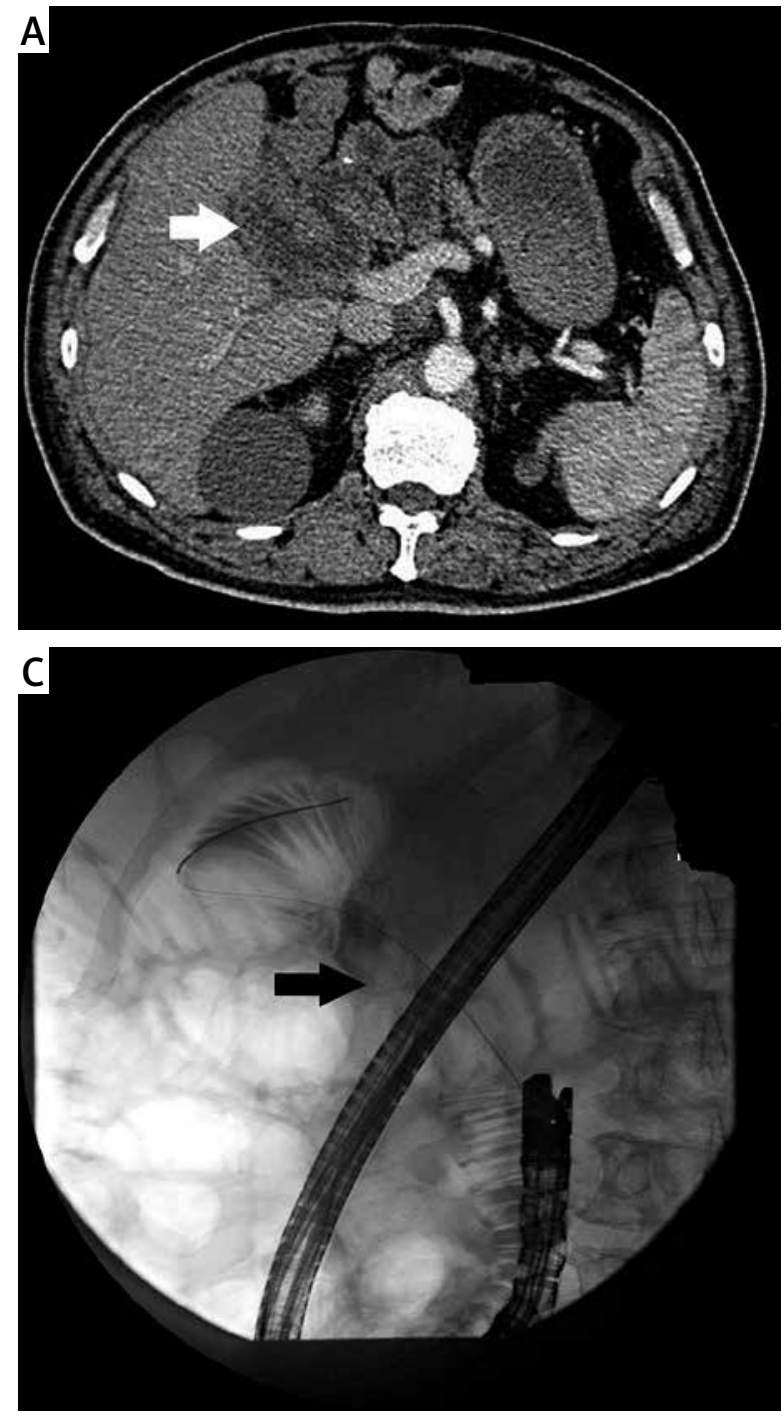

showed the following abnormalities: alanine aminotransferase, $140 \mathrm{U} / \mathrm{l}$; and alkaline phosphatase, $335 \mathrm{U} / \mathrm{l}$. His carbohydrate antigen 19-9 was $1096 \mathrm{U} / \mathrm{ml}$. The performed abdominal CT scan showed dilation of the afferent loop and pneumatosis in the afferent loop (Photo $3 \mathrm{~A}$ ). He was diagnosed with malignant ALS and management of endoscopic enteral stent (intestinal stent, Micro-Tech Nanjing Co., Ltd.) placement was performed. After stent placement, the CT scan showed the uncovered metal stent with good expansion and alleviation of the dilated afferent loop (Photo 3 B). The patient made an uneventful recovery 3 days after the procedure. He remained well without recurrent ALS during the follow-up.

Our literature analysis found a total of 49 cases (Table I) subjected to selection criteria. Including our

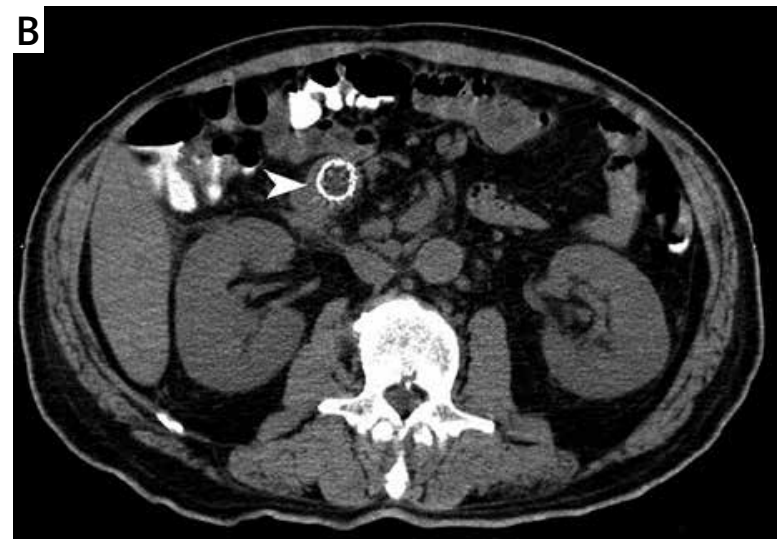

Photo 1. A - A dilated loop (white arrow), B - metal stent (arrowhead) and alleviation of dilated loop, $\mathbf{C}-3 \mathrm{~cm}$ stricture under the X-ray (black arrow)

3 cases, the total number of patients was 52 . The clinical characteristics and treatments of these patients are shown in Table II. Forty-six patients had detailed documented symptom assessment, and the most common presenting symptom or sign was jaundice ( $n=26,56.5 \%)$. Other common symptoms included upper abdominal pain ( $n=21,45.7 \%)$, fever $(n=12,26.1 \%)$, and vomiting ( $n=11,23.9 \%$ ). For 45 patients the etiology of ALS was reported; the most common reason was cancer recurrence $(n=27$, $60.0 \%$ ). The mean time from prior surgery to the diagnosis of ALS was 13.3 months.

A few strategies were used in the treatment of ALS, including endoscopic approaches, percutaneous stenting or drainage, surgery, and the conservative method, with the rates of $40.4 \%, 32.7 \%, 11.5 \%$, and 

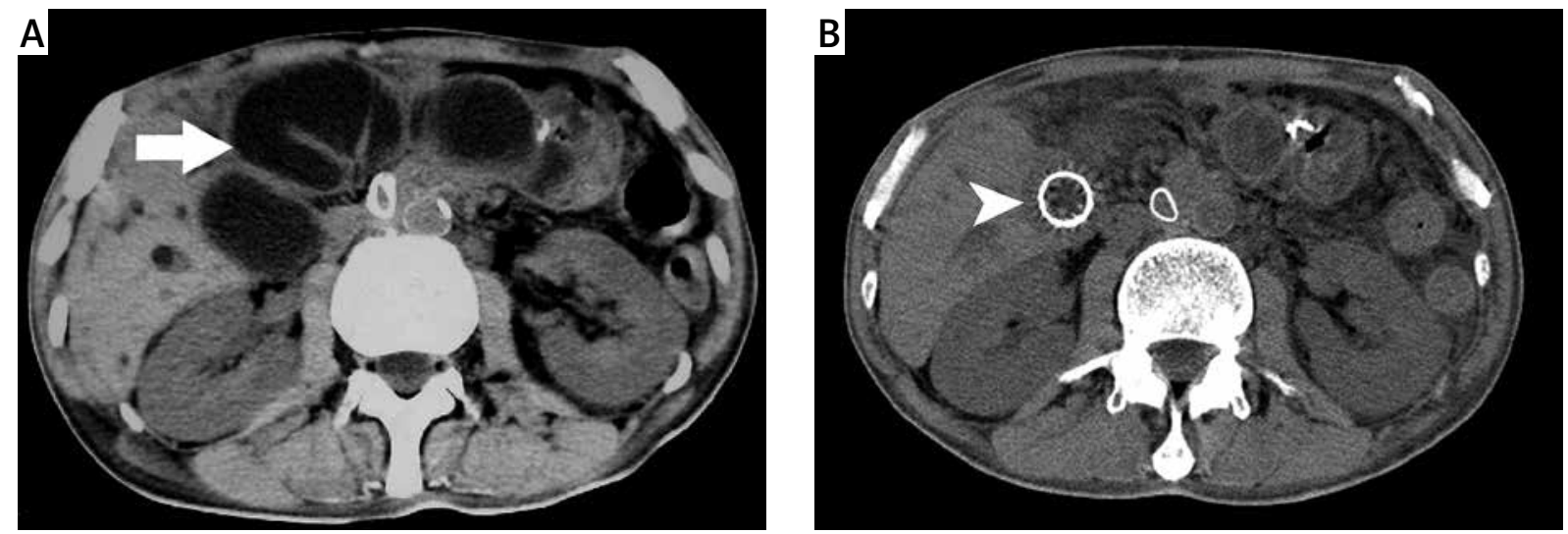

Photo 2. A - A dilated afferent loop (arrow) with the configuration like a "C" character and keyboard sign, B - metal stent (arrowhead) and alleviation of dilated loop
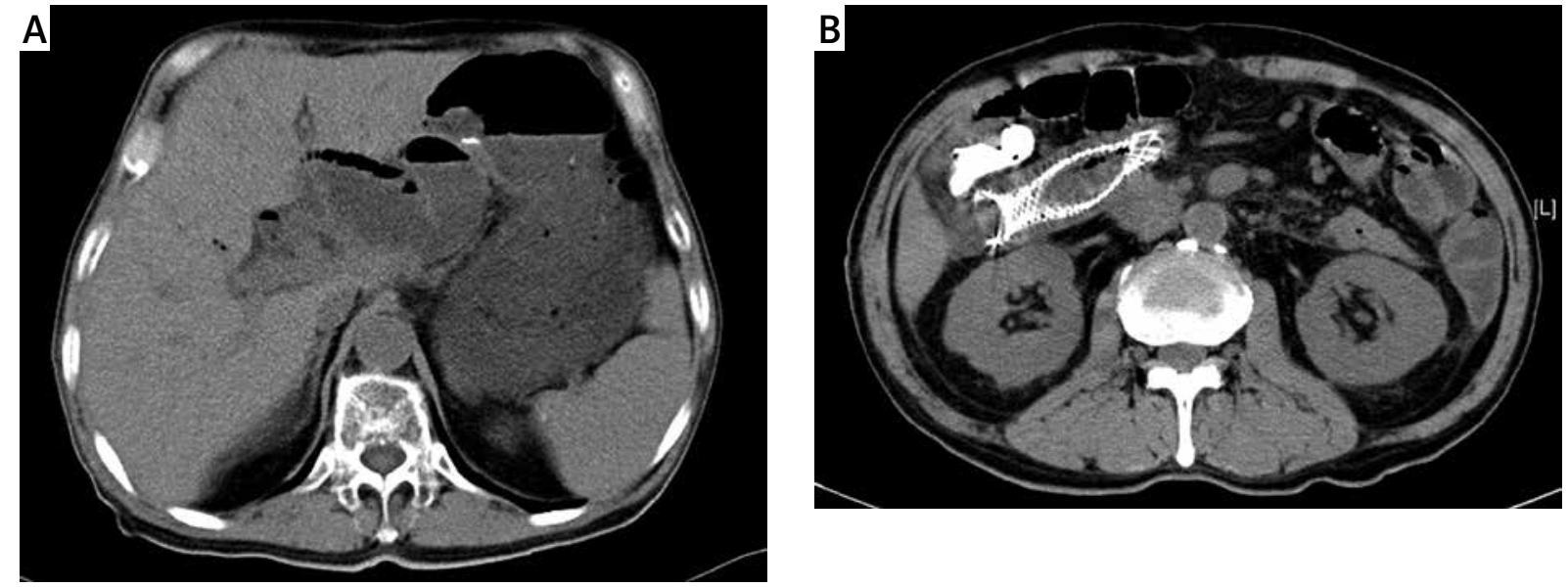

Photo 3. A - The CT scan showing dilated afferent loop and pneumatosis in the afferent loop, B - CT scan showing uncovered metal stent with good expansion and alleviation of dilated afferent loop

$15.4 \%$, respectively. Endoscopic approaches including enteral metal stent placement, double-pigtail stent placement, and balloon dilation were performed in 21 (40.4\%) patients. Nine patients treated with a double-pigtail stent had improvement of obstruction, but 3 of these patients required further treatments due to the recurrent ALS. Eight patients were treated with endoscopic enteral metal stenting. Seven of these patients showed a good outcome without complications after the procedure. The endoscopic procedure failed in 1 patient because the intestinal angulation and the obstruction were very tight. The stent remained poorly expanded despite being placed successfully, and the patient underwent a surgical bypass later. In 3 patients treated with balloon dilation alone and 1 patient treated with endoscopic plastic stent placement ALS was successfully resolved.
Seventeen $(32.7 \%)$ patients were treated by percutaneous stenting or drainage. Eleven patients with percutaneous transhepatic enteral metal stenting showed improvement of the obstruction and had no complications after the procedure. Four patients were successful in relieving the symptoms of ALS after percutaneous transhepatic biliary drainage (PTBD) without resolving the loop obstruction. One patient was treated with direct percutaneous external drainage of the dilated afferent loop, but peritonitis occurred after the procedure. One patient who underwent direct percutaneous stent placement suffered from the complication of bile leakage and infection at the puncture site.

Surgical procedures were performed in 6 (11.5\%) patients to resolve ALS. All of them succeeded in resolving the symptom of ALS. No complication after surgery was reported in these patients. Eight (15.4\%) 
Table II. Clinical characteristics and treatments of the cases

\begin{tabular}{|c|c|c|}
\hline Variable & \multicolumn{2}{|c|}{$N(\%)$} \\
\hline Manifestation: & \multicolumn{2}{|c|}{46} \\
\hline Jaundice & \multicolumn{2}{|c|}{$26(56.5)$} \\
\hline Abdominal pain & \multicolumn{2}{|c|}{$21(45.7)$} \\
\hline Fever & \multicolumn{2}{|c|}{$12(26.1)$} \\
\hline Vomiting & \multicolumn{2}{|c|}{$11(23.9)$} \\
\hline Etiology: & \multicolumn{2}{|c|}{45} \\
\hline Current cancer & \multicolumn{2}{|c|}{$27(60)$} \\
\hline Radiation enteropathy & \multicolumn{2}{|c|}{$9(20)$} \\
\hline Angulated/fixed limb: & \multicolumn{2}{|c|}{$4(8.9)$} \\
\hline Idiopathic & \multicolumn{2}{|c|}{$3(6.7)$} \\
\hline Adhesion & \multicolumn{2}{|c|}{$2(4.4)$} \\
\hline Treatments of ALS & 52 & Complication \\
\hline Endoscopic approach: & $21(40.4)$ & \\
\hline Double-pigtail stent & $9(17.3)$ & $\begin{array}{c}3 \text { recurrent } \\
\text { ALS }\end{array}$ \\
\hline Enteral metal stent & $8(15.4)$ & None \\
\hline Balloon dilation & $3(5.8)$ & None \\
\hline Plastic stent & $1(1.9)$ & None \\
\hline $\begin{array}{l}\text { Percutaneous stenting } \\
\text { or drainage: }\end{array}$ & $17(32.7)$ & \\
\hline $\begin{array}{l}\text { Percutaneous trans- } \\
\text { hepatic enteral stent }\end{array}$ & $11(21.1)$ & None \\
\hline PTBD & $4(7.7)$ & None \\
\hline $\begin{array}{l}\text { Direct percutaneous } \\
\text { stent }\end{array}$ & $1(1.9)$ & $\begin{array}{c}\text { Bile leakage, } \\
\text { infection }\end{array}$ \\
\hline $\begin{array}{l}\text { Direct percutaneous } \\
\text { external drainage }\end{array}$ & $1(1.9)$ & Peritonitis \\
\hline Surgery & $6(11.5)$ & None \\
\hline Conservative method & $8(15.4)$ & None \\
\hline
\end{tabular}

patients selected conservative treatment. Conservative treatment sometimes palliated the symptoms of ALS, but it did not completely resolve the ALS, and further treatments were required.

\section{Discussion}

Afferent loop syndrome is a rare complication, with a reported incidence of $0.2 \%$ to $20 \%$, which occurs after partial gastrectomy with Billroth-II type gastrojejunostomy, but it is not such a rare complication of other surgical procedures, such as PD [5]. Pannala et al. [1] reported that the incidence of ALS following PD for pancreatic carcinoma was $13 \%$. Juan et al. [6] observed that $7.5 \%$ (6 of 80 ) of patients suffered from ALS following Whipple's operation. Afferent limb obstruction is usually caused by mechanical obstruction from kinking of the afferent limb, radiation enteritis, internal hernias, or compression of the afferent limb by postoperative adhesions or tumor recurrence. The most important etiology of ALS after PD is recurrent cancer, and ALS more often develops in patients treated with relatively intense chemoradiation protocols [1]. Considering that survival of patients with pancreatic carcinoma improved due to the development of chemotherapy and surgery, the incidence of ALS following PD has the possibility of increasing.

Most cases of ALS following PD are malignant and may be fatal if cholangitis or jaundice develops $[5,7]$. Obstruction of the afferent loop with progressive accumulation of biliary, pancreatic, and intestinal secretions results in afferent loop dilatation, subsequent dilatation of the biliary tract, cholangitis, jaundice, and pancreatitis [8].

The clinical manifestations of ALS include $a b-$ dominal pain, nausea, vomiting, fever, and obstructive jaundice. These symptoms are usually relatively nonspecific and the reason for delayed diagnosis. Our analysis shows that the most common clinical presentations of ALS are jaundice, abdominal pain, fever, and vomiting, with the rate of $56.5 \%$, $45.7 \%, 26.1 \%$, and $23.9 \%$, respectively. Increased white blood cell count, alanine aminotransferase, and total bilirubin are common in ALS. The jaundice and fever are actually the manifestation of acute cholangitis, and the clinical symptoms of ALS are mainly caused by acute cholangitis. The symptoms and abnormal laboratory tests show a high rate of cholangitis in patients with ALS after PD. We believe that, without the sphincter of Oddi, cholangiectasis and cholangitis are more common than in the ALS after subtotal gastrectomies. The high incidence of cholangiectasis and cholangitis is the major characteristic of ALS after PD.

The diagnosis of ALS is based on the clinical presentation, the history of surgery, abnormal laboratory tests, and typical findings on CT scan. The symptoms of ALS are usually vague and non-specif- 
ic. Some ALS are even found asymptomatically by imaging examination in the follow-up [7]. Due to the chronic and non-specific presentation, combining clinical presentation with imaging or endoscopic examination may be useful in diagnosing ALS. The causes of afferent loop obstruction can be correctly predicted by axial plane CT in most cases [9]. Juan et al. [6] opined that multidetector-row CT (MDCT) with coronal reformation is superior to axial plane CT in some cases, and they affirmed that a fluid-filled C-shaped afferent loop on the coronal plane in combination with valvulae conniventes projecting into the lumen (keyboard sign) was the most common and typical MDCT feature of ALS. In addition, MDCT with coronal reformation displays more bowel loops in a single image, which is necessary to evaluate ALS and suggests the underlying causes of ALS. In over $80 \%$ of the cases in our study, ALS was confirmed by CT scan. Magnetic resonance cholangiopancreatography (MRCP) can be a very useful guide in the operation for ALS, whereas modern MDCT scanners can easily provide coronal reformats that would give similar information to the image provided by MRCP [10]. The ultrasonographic appearance of ALS is that of a large dilated bowel loop in the mid abdomen, but it is difficult to differentiate confidently from a pancreatic pseudocyst [11]. The conventional barium swallow study is not a good choice for diagnosis, because non-obstructed afferent loops are not filled by barium solution in $20 \%$ of cases [11].

There are several therapeutic strategies for the ALS after PD, including surgical procedures such as radical resection, surgical bypass (jejunojejunostomy, Roux-en-Y bypass, and jejunostomy) or nonsurgical treatments such as drainage (external or internal), balloon dilation, and stent placement by the peroral, direct percutaneous, or percutaneous transhepatic approach [4]. The therapist should evaluate carefully and choose the appropriate treatment for the individual cases.

Traditionally, surgical procedures were considered to be the first choice to resolve ALS. Surgery is effective but largely invasive. Many patients with malignant ALS are not well enough to tolerate a surgical procedure. Palliative surgical revisions were only successfully performed in $75 \%$ of patients with ALS because of their poor general condition, peritoneal adhesion, or disseminated tumor [12]. In the retrospective reports, we find that surgery was mostly performed in the earlier reported cases. Al- ternatively, more and more clinicians are inclined to choose less invasive or non-surgical procedures.

Percutaneous catheter drainage is a successful method of palliation in the treatment of closed-loop small bowel due to recurrent adenocarcinoma of the colon [13]. Percutaneous insertion of a catheter into a blind loop obstructed by a malignant neoplasm has been described when the distended afferent loop underlies the anterior abdominal wall $[5,12,14]$. In an experimental study, van Sonnenberg et al. [15] reported the escape of gas into the peritoneal cavity with percutaneous drainage of the canine bowel dilated by air, using a variety of catheters (7 to $9 \mathrm{Fr}$ ) and techniques. Apart from the risk of leakage of enteral gas and content, which may cause peritonitis, the nursing care of the catheter and the loss of fluid and electrolytes with the bile juice limit the application of percutaneous catheter drainage [7, 12]. Only 1 patient in our series was treated by direct percutaneous insertion of a catheter, and he suffered from the complication of bile leakage and infection at the puncture site.

There was no complication found after percutaneous transhepatic approaches in the series we studied. Nevertheless, the percutaneous approach including PTBD is contraindicated in patients with malignant ascites or multiple liver metastases, and the combined effect of the increasing intrabiliary pressure and reflux of bacteria from the obstructive loop would lead to severe cholangitis even if biliary drainage were effective $[5,14]$. The PTBD may be a good choice when the patient cannot bear surgery and the stent fails to be inserted through the stricture, but permanent external drainage is always an unsatisfactory approach, regardless of the loss of fluid and electrolytes. Meanwhile we find that there are few reports about percutaneous transhepatic stent placement in the stricture of the afferent loop for ALS after gastrectomy, because cholangiectasis rarely occurs in these cases.

Burdick et al. [16] reported a case of ALS of malignant etiology managed by transoral catheter, which provided a diagnostic and therapeutic purpose and made a satisfactory palliation with improvement in symptoms such as abdominal pain and vomiting. However, this approach is temporary, and an enteral metallic stent needs to be placed to achieve a longterm outcome.

Nine patients were treated with double-pigtail stent placement in the afferent loop in a single 
center, and 7 of 9 patients showed improvement of symptoms. Three of these 7 patients required further treatment due to the recurrent ALS caused by locally recurrent cancer. A plastic stent including a double-pigtail stent cannot provide a long-term outcome, especially in malignant ALS.

Although the treatment for ALS is performed to relieve jaundice and no food needs to pass through the stricture, the afferent loop occlusion should be regarded as a conventional small bowel obstruction requiring enteral stent insertion [7]. The reconstruction of the digestive tract after PD is more complicated than that after gastrectomy, so more individual treatments are necessary. It is important but not sufficient to relieve cholangitis in the treatment of ALS; like the treatment of conventional small bowel obstruction, the final purpose of treatment is to resolve the intestinal obstruction. Optimal treatment requires free flow from the afferent loop to the efferent loop. Catheter, plastic stent, balloon dilation, and conservative treatment are not enough to provide a long-term outcome, and plastic stent and balloon dilation is used for patients without local cancer recurrence.

There are several different routes of stent insertion for treating ALS: the direct percutaneous, percutaneous transhepatic and peroral routes. A direct percutaneous stent is only used when the afferent loop is underlying close to the anterior abdominal wall, but the afferent loop is usually not fixed to the abdominal wall, and the leakage of enteral gas and content into the peritoneal cavity is unavoidable. The percutaneous transhepatic route is also restricted in patients with ascites or multiple liver metastases, and passing a guidewire through the stricture of the loop is not possible every time by the percutaneous transhepatic route. In the early reports, some authors believed that, with the change and reconstruction of the upper gastrointestinal tract due to previous surgery, stent insertion by the transoral endoscopic route was not available in most cases [17-19]. However, due to the development of the endoscopic technique, stent placement through the peroral approach with the endoscope is adopted by more and more clinicians. In our previous observation, the gastroscope can reach the site of biliary anastomosis of the afferent loop in over $80 \%$ of patients after PD, and can reach the pancreatic anastomosis in over $70 \%$ of cases, if it is performed by an experienced endoscopy physician. We believe the endoscope could reach the stricture of the loop in most patients, especially when the lesion is not far from the gastrointestinal anastomosis. Meanwhile, close to the lesion it is very helpful to make the guidewire pass through the stricture of the bow$\mathrm{el}$, and the placement of the guidewire is essential to the stent placement. The main cause of failure of peroral stent placement is that the endoscope cannot reach the lesion of the loop. When peroral stent placement is impossible, the percutaneous transhepatic approach should be considered [20]. In our study, the patients treated with endoscopic enteral metal stent placement enjoyed a long-term outcome with good patency of the metal stent. None of them had complications after stent placement and recurrent ALS. Compared with the catheter and plastic stent, a metal stent provides more sufficient dilation in resolving the afferent loop obstruction for the long-term outcome.

Endoscopic therapeutic interventions and their efficacy in ALS after PD have not been evaluated before. In the series we analyzed, in the patients treated with endoscopic metal enteral stent placement the ALS effectively resolved and there were no complications or recurrent ALS in the follow-up. In our cases, we chose to use a colonoscope, because as a front mirror endoscope, the colonoscope is easy to control and can go further in the reconstructed gastrointestinal tract, and the unreleased metal stent can pass through the operation channel of the colonoscope directly.

Our study showed that $60.0 \%$ of cases of ALS after PD were malignant. Surgery cannot completely resolve the problem of tumor recurrence, and most of the patients are not well enough to tolerate major invasive surgery. Endoscopic enteral stent placement has minimal invasiveness and fewer complications, without the loss of fluid and electrolytes, so it proves to be a preferential option in the treatment of malignant ALS. Surgery may be the last choice for patients if the endoscopic approach has failed and the patients' general condition could be improved in a short period of time.

\section{Conclusions}

Cases of ALS following PD are rarely reported in the literature. Most of these ALS are malignant. The patient's general condition, the site of obstruction, postoperative anatomy, and symptoms must be tak- 
en into consideration when choosing an appropriate treatment procedure. Therapeutic effects of ALS are obvious, but the long-term outcome is not easy to evaluate, because most patients have a poor prognosis. Our study shows that insertion of endoscopic enteral metal stents effectively treats cholangitis and resolves ALS, improves quality of life in the postprocedural period, and recurrence of ALS was not found in the follow-up in any cases. We believe that endoscopic enteral metal stent placement is the first choice of treatment for malignant ALS after PD because it is safe, minimally invasive and effective, with a relatively high success rate.

\section{Conflict of interest}

The authors declare no conflict of interest.

\section{References}

1. Pannala R, Brandabur JJ, Gan SI, et al. Afferent limb syndrome and delayed $\mathrm{Gl}$ problems after pancreaticoduodenectomy for pancreatic cancer: single-center, 14-year experience. Gastrointest Endosc 2011; 74: 295-302.

2. Eagon JC, Miedema BW, Kelly KA. Postgastrectomy syndromes. Surg Clin North Am 1992; 72: 45-65.

3. Aoki M, Saka M, Morita S, et al. Afferent loop obstruction after distal gastrectomy with Roux-en-Y reconstruction. World I Surg 2010; 34: 2389-92.

4. Hosokawa I, Kato A, Shimizu H, et al. Percutaneous transhepatic metallic stent insertion for malignant afferent loop obstruction following pancreaticoduodenectomy: a case report. J Med Case Rep 2012; 6: 198.

5. Aimoto T, Uchida E, Nakamura Y, et al. Malignant afferent loop obstruction following pancreaticoduodenectomy: report of two cases. J Nippon Med Sch 2006; 73: 226-30.

6. Juan YH, Yu CY, Hsu HH, et al. Using multidetector-row CT for the diagnoses of afferent loop syndrome following gastroenterostomy reconstruction. Yonsei Med I 2011; 52: 574-80.

7. Laasch HU. Obstructive jaundice after bilioenteric anastomosis: transhepatic and direct percutaneous enteral stent insertion for afferent loop occlusion. Gut Liver 2010; 4: S89-95.

8. Wise SW. Case 24: afferent loop syndrome. Radiology 2000; 216: $142-5$.

9. Kim HC, Han JK, Kim KW, et al. Afferent loop obstruction after gastric cancer surgery: helical CT findings. Adom Imaging 2003; 28: 624-30.

10. Ashida A, Tamura I, Kumagiri Y, et al. Magnetic resonance cholangiopancreatography for afferent loop syndrome. ANZ I Surg 2008; 78: 91-2.

11. Gayer G, Barsuk D, Hertz M, et al. CT diagnosis of afferent loop syndrome. Clin Radiol 2002; 57: 835-9.

12. Moriura S, Takayama Y, Nagata J, et al. Percutaneous bowel drainage for jaundice due to afferent loop obstruction following pancreatoduodenectomy: report of a case. Jpn I Surg 1999; 29: 1098-101.
13. Bezreh JS. Percutaneous catheter drainage of closed-loop small bowel obstruction. AJR Am J Roentgenol 1983; 141: 797-8.

14. Kim YH, Han JK, Lee KH, et al. Palliative percutaneous tube enterostomy in afferent loop syndrome presenting as jaundice: clinical effectiveness. J Vasc Interv Radiol 2002; 13: 845-9.

15. van Sonnenberg E, Verney RR, Casola G, et al. Percutaneous cecostomy for Ogilvie syndrome: laboratory observation and clinical experience. Radiology 1990; 17: 574-6.

16. Burdick JS, Garza AA, Magee DJ, et al. Endoscopic management of afferent loop syndrome of malignant etiology. Gastrointest Endosc 2002; 55: 602-5.

17. Johnsson E, Delle M, Lundell L, et al. Transhepatic placement of an enteral stent to treat jaundice in a tumor recurrence obstructed afferent loop after a Whipple procedure. Dig Surg 2003; 20: 329-31.

18. Yao NS, Wu CW, Tiu CM, et al. Percutaneous transhepatic duodenal drainage as an alternatice approach in afferent loop obstruction with secondary obstructive jaundice in recurrent gastric cancer. Cardiovasc Intervent Radiol 1998; 21: 350-3.

19. Caldicott DG, Ziprin P, Morgan R. Transhepatic insertion of a metallic stent for the relief of malignant afferent loop obstruction. Cardiovasc Inter Radiol 2000; 23: 138-15.

20. Han K, Song HY, Kim JH, et al. Afferent loop syndrome: treatment by means of the placement of dual stents. AJR Am J Roentgenol 2012; 199: W761-6.

21. Matsumoto K, Kato H, Tomoda T, et al. A case of acute afferent loop syndrome treated by transgastric drainage with EUS. Gastrointest Endosc 2013; 77: 132-3.

22. Kim JK, Park CH, Huh JH, et al. Endoscopic management of afferent loop syndrome after a pylorus preserving pancreatoduodenecotomy presenting with obstructive jaundice and ascending cholangitis. Clin Endosc 2011; 44: 59-64.

23. Spiliotis J, Karnabatidis D, Vaxevanidou A, et al. Acute cholangitis due to afferent loop syndrome after a Whipple procedure: a case report. Cases J 2009; 2: 6339.

24. Chevallier P, Novellas S, Motamedi JP, et al. Percutaneous jejunostomy and stent placement for treatment of malignant Roux-en-Y obstruction: a case report. Clin Imaging 2006; 30 : 283-6.

Received: 21.10.2014, accepted: 8.03.2015. 